\title{
Review Article \\ Review of Blast Loading Models, Masonry Response, and Mitigation
}

\author{
Eid Badshah, ${ }^{1}$ Amjad Naseer, ${ }^{1}$ Muhammad Ashraf, ${ }^{1}$ Feroz Shah, ${ }^{2}$ and Kareem Akhtar ${ }^{2}$ \\ ${ }^{1}$ Department of Civil Engineering, UET Peshawar, Peshawar, Pakistan \\ ${ }^{2}$ Department of Mechanical Engineering, UET Peshawar, Peshawar, Pakistan \\ Correspondence should be addressed to Amjad Naseer; amjad_naseer@yahoo.com
}

Received 12 April 2017; Revised 3 July 2017; Accepted 3 August 2017; Published 29 November 2017

Academic Editor: Abdul Qadir Bhatti

Copyright (c) 2017 Eid Badshah et al. This is an open access article distributed under the Creative Commons Attribution License, which permits unrestricted use, distribution, and reproduction in any medium, provided the original work is properly cited.

\begin{abstract}
Different models for prediction of blast loading, response of masonry structure against blast load, and various mitigation strategies are discussed. Variation of peak positive incident pressure with scale distance in free field spherical burst and surface burst scenarios, proposed by different researchers, is presented and compared. The variation is found significant in the region of small scaled distances. Blast wave parameters in urban environment have been found different from the free field scenario. Effects of geometry, boundary conditions, and material properties on response of masonry buildings were found significant. Different mitigation strategies such as blast wall, landscaping, architecture, and retrofitting techniques are presented.
\end{abstract}

\section{Introduction}

Terrorism has played havoc with civilian and public infrastructure by use of explosive materials for the last several decades. Bird's eye view on the incidents of terrorism speaks volumes for vulnerability of public buildings along with security installations to blast loading. The situation is becoming increasingly alarming due to simple techniques required for synthesis of explosive material from urea and fuel oil freely available in open market. The situation has been complicated further as the available literature for prediction of blast loads and response of structure is limited and qualitative in nature. Most of quantitative research and design guidelines developed since World War I are classified and limited to military establishments. However, several researchers have developed models, tables, and charts for predicting shock wave parameters on the basis of scaled distance $(Z=$ $\left.R / W^{1 / 3}\right)$. The results are largely scattered in the region of small scaled distances.

Blast results in extreme loading conditions against the nearby structures resulting in damage, shrapnel, and complete collapse. Percentage of injuries and deaths is greater due to impinging high velocity projectiles discharged from the structural elements than the direct shock waves in terrorist bombing and accidental explosion. Furthermore, response of structure is dependent on relative position of point of detonation with respect to structure as well as ground surface, type and quantity of explosive used, natural time period, geometry, boundary conditions, and material properties of target structure.

A structure cannot be made safe completely against a defined threat level; however, the damages can be controlled by using different techniques. Various mitigation strategies can be used. These include strict surveillance of intelligence and security agencies, increasing stand-off distance between the centre of explosion and target structure using physical barriers, fabricating blast walls for attenuation of shock wave parameters before reaching the target structure, proper landscaping of site, optimizing orientation and architecture of structure, redetailing of structural elements, using energy absorbing materials, and hardening the structures by retrofitting techniques.

\section{Pressure-Time History and Pressure Models}

Blast load is an extreme and complex event characterized by abrupt increase to peak value of pressure and decaying 


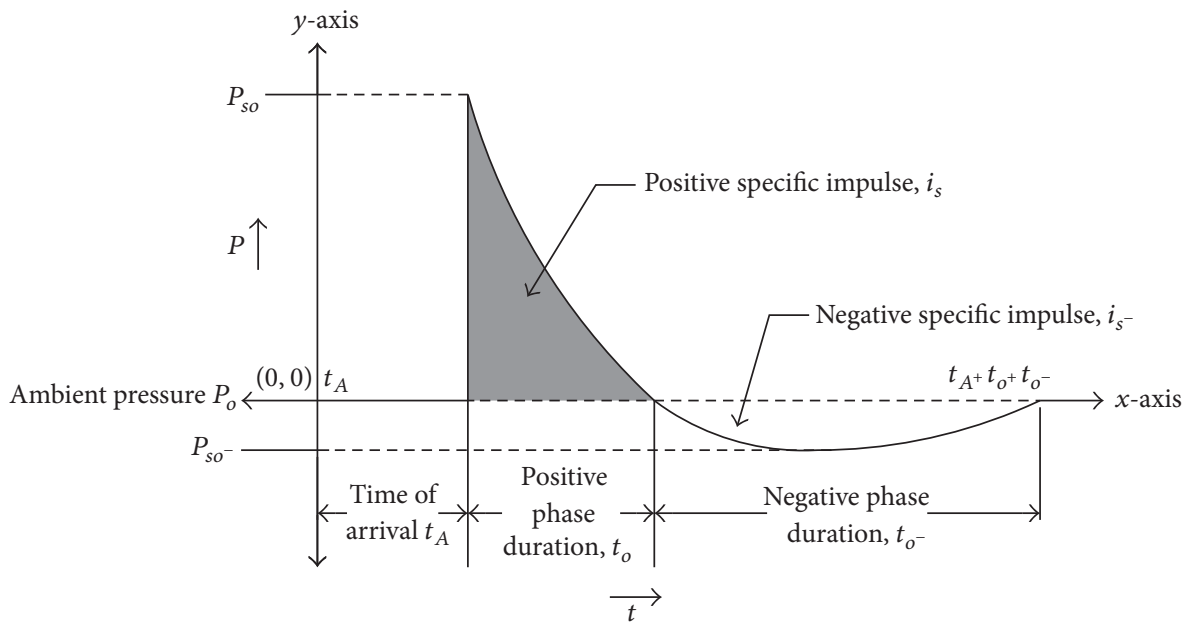

FIGURE 1: Pressure-time history (reproduced from UFC 3-340-02 [1]).

to atmospheric pressure, in microseconds. Simplified and typical pressure-time history is shown in Figure 1.

Pressure $(P)$ is shown on $y$-axis and time $(t)$ on $x$ axis. The ambient pressure $P_{o}$ is shown as reference or zero pressure for the positive and negative pressure values. After explosion, the blast wave front reaches a target point in time $t_{A}$ and in no time reaches peak incident pressure $P_{s o}$ which is the maximum positive pressure and then promptly decays to atmospheric pressure $P_{o}$. The trend continues in the negative direction and reaches peak negative pressure $p^{-}{ }_{s o}$. It is followed by further pulsations which are considered insignificant. Incident peak overpressure $\left(P_{s o}\right)$ is important parameters for finding the response and design of structure against blast loading.

Researchers have developed models for peak positive incident pressure $\left(P_{s o}\right)$ along with other parameters of shock wave for free air burst and surface burst scenarios. For surface burst, the TNT equivalent weight in free air burst shall be increased by $70-80 \%$ to account for earth surface reflection and consequent reinforcement (Karlos et al. [2]). Surface reflection and reinforcement is mainly dependent on the nature of base materials. Ullah et al. [3] reported reflection factors for commonly used base materials. Similarly, shape of explosive and its point of ignition affect positive overpressure. Badshah [4] found attenuated reflection of blast waves from ground surface for cylindrical shaped explosives when ignited at top flat face.

2.1. Free Air Burst Models. Brode model [5] is

$$
\begin{aligned}
& P_{\text {so }}=\frac{0.67}{Z^{3}}+0.1, \quad\left(P_{\text {so }}>1\right), \\
& P_{\text {so }}=\frac{0.0975}{Z}+\frac{0.1455}{Z^{2}}+\frac{0.585}{Z^{3}}-0.0019,
\end{aligned}
$$

$$
\left(0.01<P_{s o}<1\right) \text {. }
$$

Henrych and Major model [6] is

$$
\begin{aligned}
P_{\text {pos }}=\frac{1.4072}{Z}+\frac{0.5540}{Z^{2}}-\frac{0.0357}{Z^{3}}+\frac{0.000625}{Z^{4}}, \\
(0.05<Z>0.3),
\end{aligned}
$$

$$
\begin{aligned}
& P_{\text {pos }}=\frac{0.6194}{Z}-\frac{0.0326}{Z^{2}}+\frac{0.2132}{Z^{3}}, \quad(0.3 \leq Z \leq 1), \\
& P_{\text {pos }}=\frac{0.0662}{Z}+\frac{0.405}{Z^{2}}+\frac{0.3228}{Z^{3}}, \quad(1 \leq Z<10) .
\end{aligned}
$$

Held model [7] is

$$
P_{\text {pos }}=2 \frac{W^{2 / 3}}{R^{2}}
$$

Kinny and Graham model [8] is

$$
\begin{aligned}
P_{\mathrm{pos}} & =P_{o} \\
\cdot & \frac{80.8\left[1+(Z / 4.5)^{2}\right\rceil}{\sqrt{\left[1+(Z / 0.048)^{2}\right\rceil} \times \sqrt{\left[1+(Z / 0.32)^{2}\right\rceil X \sqrt{\left[1+(Z / 1.35)^{2}\right\rceil}}} .
\end{aligned}
$$

Mills model [9] is

$$
P_{\text {pos }}=\frac{1.772}{Z^{3}}-\frac{0.114}{Z^{2}}+\frac{0.108}{Z} .
$$

Sadovskiy model [10] is

$$
P_{\text {pos }}=0.085 \frac{W^{1 / 3}}{R}+0.3\left\lceil\frac{W^{1 / 3}}{R}\right\rceil^{2}+0.8\left\lceil\frac{W^{1 / 3}}{R}\right]^{3} .
$$

Bajic model [11] is

$$
P_{\text {pos }}=0.102 \frac{W^{1 / 3}}{R}+0.436 \frac{W^{1 / 3}}{R^{2}}+1.4 \frac{W}{R^{3}} .
$$

TM5-855-1 model [12] is

$$
\begin{aligned}
P_{\mathrm{pos}}=\frac{4120}{Z^{3}}-\frac{105}{Z^{2}}+\frac{39.5}{Z} & \\
& \text { for }\left(2<P_{\text {so }}<160\right),(3<Z<20) .
\end{aligned}
$$


2.2. Surface Burst Models. Newmark and Hansen model [13] is

$$
P_{s o}=0.6784 \frac{W}{R^{3}}+0.294 \frac{W^{1 / 2}}{R^{3 / 2}} .
$$

Swisdak model [14] is

$$
\begin{aligned}
P_{\text {pos }} & =\left(\exp A+B \times \ln (Z)+C \times(\ln (Z))^{2}+D\right. \\
& \times(\ln (Z))^{3}+E \times(\ln (Z))^{4}+F \times(\ln (Z))^{5}+G \\
& \left.\times(\ln (Z))^{6}\right) \times 10^{-3} .
\end{aligned}
$$

Wu and Hao model [15] is

$$
\begin{aligned}
& P_{\text {pos }}=1.059\left\lceil\frac{R}{W^{1 / 3}}\right]^{-2.56}-0.051, \\
& \text { for }\left(0.1 \leq \frac{R}{W^{1 / 3}} \leq 1\right), \\
& P_{\text {pos }}=1.008\left\lceil\frac{R}{W^{1 / 3}}\right]^{-2.01}, \quad \text { for }\left(1<\frac{R}{W^{1 / 3}} \leq 10\right) .
\end{aligned}
$$

Siddiqui and Ahmad model [16] is

$$
P_{\text {pos }}=1.017\left\lceil\frac{R}{W^{1 / 3}}\right\rceil^{-1.91}, \quad \text { for }\left(1 \leq \frac{R}{W^{1 / 3}} \leq 12\right) \text {. }
$$

Ahmad et al. model [17] is

$$
P_{\text {pos }}=2.46\left\lceil\frac{R}{W^{1 / 3}}\right]^{-2.67} .
$$

Iqbal and Ahmad model [18] is

$$
P_{\text {pos }}=1.026\left\lceil\frac{R}{W^{1 / 3}}\right\rceil^{-1.96}, \quad \text { for }\left(1 \leq \frac{R}{W^{1 / 3}} \leq 12\right) \text {. }
$$

Badshah model [4] is

$$
P_{r}=4.34 \times Z^{-2.84},
$$

where " $W$ " is TNT equivalent weight $(\mathrm{kg})$, " $R$ " is stand-off distance $(\mathrm{m})$, and " $Z$ " is the scaled distanced defined below:

$$
Z=\frac{R}{W^{1 / 3}}\left(\mathrm{~m} / \mathrm{kg}^{1 / 3}\right) \text {. }
$$

All the above models for peak positive reflected overpressure are plotted in Figure 2.

Held model [7] and Brode model [5] predict the highest and lowest values, respectively, among all the investigated free air burst and surface burst models for the selected range of scaled distance $Z\left(4.353-1.830 \mathrm{~m} / \mathrm{kg}^{1 / 3}\right)$ in this study. The behavior of Held [7], Sadovskiy [10], and Bajić [11] models is strange enough as it gives even higher values than all the surface burst models. Iqbal and Ahmad model [18] and Siddiqui and Ahmad model [16] give almost same values and are placed at the centre of all plots. Similarly, Badshah [4] and Kinney and Graham model [8] demonstrate nearly the same values in the region of large scaled distances. The results for both free air burst and surface burst are scattered largely in the region of small scaled distance. Furthermore, the results of surface burst models are less scattered as compared to free air burst models. Scattering of models indicate poor investigation of blast loads in near field and variability of behavior of blast load models from near to far field scenarios.

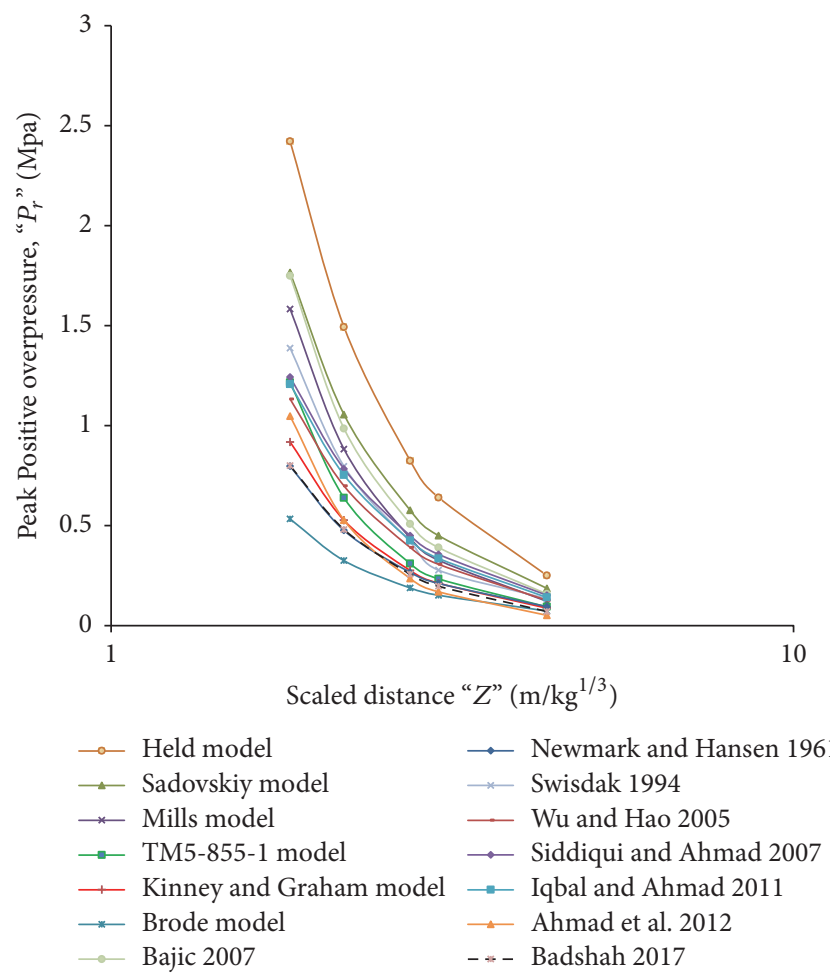

Figure 2: Comparison of blast models.

2.3. Effect of Adjacent Structures. Shock wave parameters are different in free field than urban environment for the same TNT equivalent charge weight and stand-off distance. Smith and Rose [19] reported, "regions of high and low loading do not necessarily occur where they might intuitively be expected; 'hot spots' occur where a building surface might be expected to be shielded and relatively low loads are evident where a direct line from charge to 'target' might be expected to produce a higher load." The author found that Feng followed by Whalen was among the earliest investigators who found enhanced blast wave parameters in simple straight and model city streets configurations, respectively.

Birnbaum et al. [20] used three-dimensional Eulerian FCT techniques to study the channeling effect on the blast wave parameters on the target office block near the ground, in the scenario of partial confinement of blast wave in city street as shown in Figure 3.

Blast wave parameters at the base of office block were found reinforced by the channeling effect due to the presence of other buildings and comparison with free field scenario is shown in Figure 4. Channeling effect increased peak over pressure and maximum impulse by $153 \%$ and $340 \%$, respectively, when compared with free field results using analytical model.

Johansson et al. [21] studied the effect of urban environment on the blast wave parameters. Semiempirical model AUTODYN $^{\mathrm{TM}}$ [19] based on computational fluid dynamics (CFD) was used for numerical studies. For simulating the urban environment, experimental test was carried in simple intersection comprising four concrete blocks with reduced 


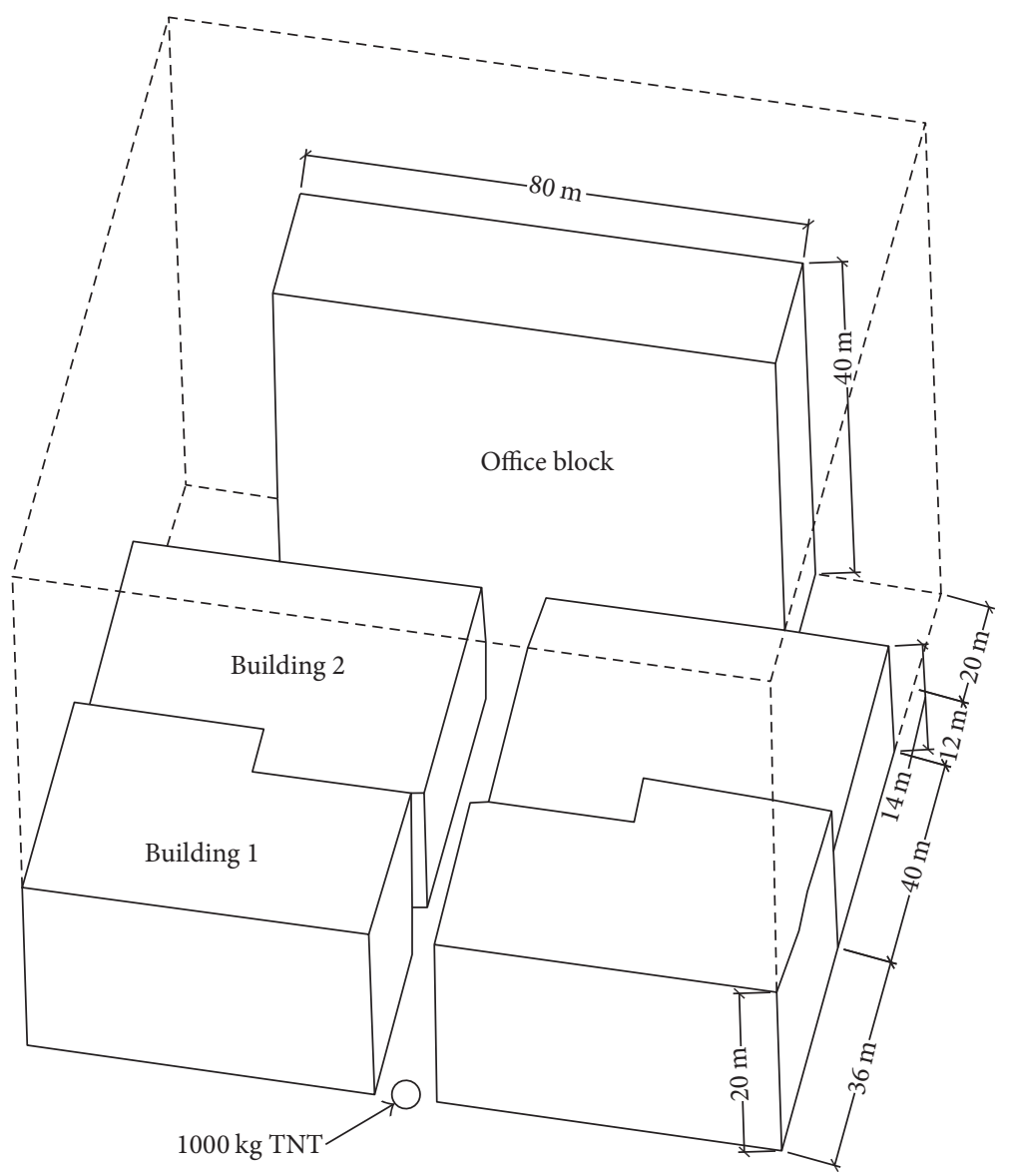

FIGURE 3: Detail of explosive placement, street, and target office block.

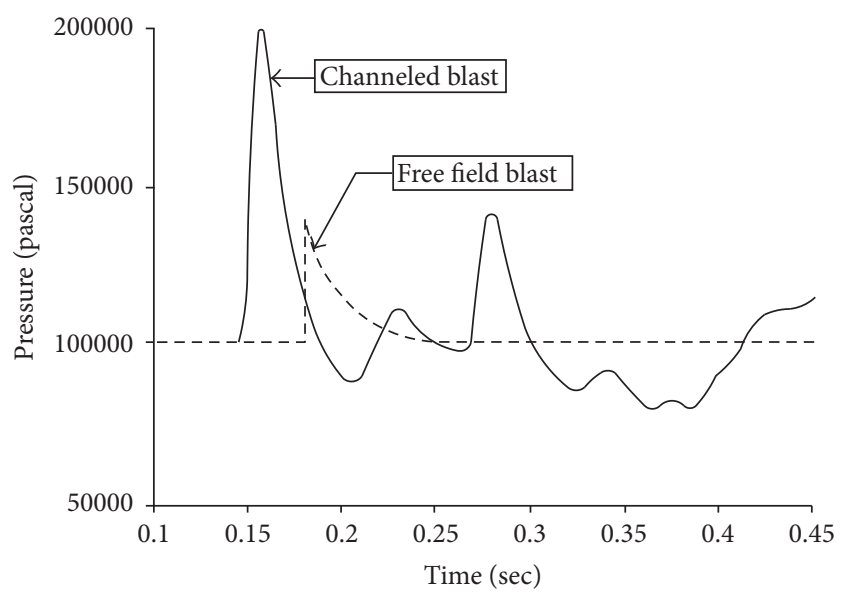

FIgURE 4: Comparison of free air field and street channeled blast pressure-time history.

scale of 1:5. Complex urban scenario changed blast wave parameters as a result of diffractions and reflections at various points in comparison to free field. Sixty-five percent (65\%) pressure-time histories of experimental and AUTODYN results showed good match and reached $\mathrm{Coh} \geq 0.5$. Furthermore, author has shown that superposition theorem with adjustment for diffraction of pressure waves where needed can be used as raw technique for estimating pressure from incident pressures and consequent load generated in complex environment. By using this technique results obtained were deviating only $20 \%$ from the experimental data.

Reminnikov [22] studied the increasing or decreasing effect on blast loads on building due to the presence of adjacent structures. Air3D program was used for numerical simulation. Blast event targeted medium sized shopping mall at the end of T-junction in a portion of straight city street. City street was 100-meter long passing through buildings of different heights $10 \mathrm{~m}, 20 \mathrm{~m}$, and $30 \mathrm{~m}$ to $40 \mathrm{~m}$. The blast environment was generated by use of $1000 \mathrm{~kg}$ TNT equivalent explosive placed on the ground surface in the middle of the street. The stand-off distance for the nearest building was $5 \mathrm{~m}$. It was observed that peak over pressure as well as positive impulse increased along the street due to multiple reflections from the adjacent structures when compared with free field surface burst explosion scenario. It was shown that all buildings with scaled height $\left(\mathrm{h} / \mathrm{W}^{1 / 3}\right)$ greater than $1.0 \mathrm{~m} / \mathrm{kg}^{1 / 3}$ provided same level confinement to the peak pressure. Similarly, all buildings with scaled height greater than $3.0 \mathrm{~m} / \mathrm{kg}^{1 / 3}$ have equal effect on positive impulse at ground level. Enhancement Design Factors (ratio of numerical and empirical values) as a function of distance for pressures and 
impulses were derived along the street. The peak reflected pressure on the target building at the $\mathrm{T}$-junction was found $300 \%$ greater than empirically (free field) measured pressure. Enhancement Factors for reflected pressure and reflected impulse remained constant on the front wall of the target building along vertical line but decreased near the top of the building due to diffraction of pressure waves over the roof.

Rose and Smith [23] studied the effect on the profile of impulse from a blast event occurring in city street bordered by representative height of buildings. Numerical study using three-dimensional Air3D program was compared to the results of reduced scale (1/40) experiments. Peak positive and negative impulses on front of buildings near the ground level were plotted against the scaled distance along the street. It was observed that street width scaled distance greater than $4.8 \mathrm{~m} / \mathrm{kg}^{1 / 3}$ does not affect the positive impulse on the near side. Similarly, buildings with scaled height more than $3.2 \mathrm{~m} /$ $\mathrm{kg}^{1 / 3}$ do not increase positive impulse significantly. Negative impulse is maximum when scaled building height reaches $12.8 \mathrm{~m} / \mathrm{kg}^{1 / 3}$. Negative phase impulse is more than positive impulse pertaining to street centre line scaled distance of $2.0 \mathrm{~m} / \mathrm{kg}^{1 / 3}$ for all widths of streets and height of buildings.

Mays and Smith [24] discussed the funneling effect of shock waves in urban environment. Authors reported that hemispherical flow of blast wave is restrained in city streets due to the reflection, refraction, and diffraction from the adjacent structures. Consequently, pressure drop with distance is more slowly which endanger relatively far off located buildings.

Effects of terrorist activities in urban centre are neither limited to target structure nor equivalent to free field environment. The effects may be devastating for structure due to channeling/funneling effect of the adjacent structures. Sophisticated numerical methods or software based on computational fluid dynamics (CFD) such as AUTODYN and Air3D may be used for accurate analysis of the structure under blast loading in complex urban environment.

\section{Structural Response}

Response of structure is dependent on blast wave parameters, natural time period, geometry, boundary conditions, and material properties of target structure.

3.1. Effect of Stand-Off Distance. Response of structure varies between local failure of structural elements and global failure of the structure depending mainly on the stand-off distance. TEK 14-2A Structural [25] reported that close-in and faraway blasts initiate local punching and flexure failure, respectively. Localized shear failure is initiated in structural element in the shape of punching, spalling producing low and high velocity debris when centre of blast is in close proximity or contact (Ngo et al. [26]). Shi et al. [27] experimentally studied local damage and fragments characterization discharging from unreinforced masonry wall subjected to near field blast scenario. Two (02) unreinforced masonry walls fabricated in $\mathrm{RC}$ frames were subjected separately to blast loads $1 \mathrm{~kg}$ and $6 \mathrm{~kg}$ TNT equivalent weight at a constant stand-off distance of $0.4 \mathrm{~m}$. For $1 \mathrm{~kg}$ TNT weight blasts, no wall local damage was observed while, for $6 \mathrm{~kg}$ TNT weight blast scenario, hole was punched in the masonry wall. Thus close range blast scenario, resulted in local damage in the shape of punching or spalling instead of flexural or shear failure of wall. Furthermore, smaller fragments scattered at larger distance and larger fragments fell in the nearby area.

Failure pattern changes into global domain as the distance between centre of explosion and structure is increased. When structure is exposed to long duration out-of-plan loading, global response in the shape of bending or shear failure is initiated (Ngo et al. [26]). Keys and Clubley [28] investigated masonry debris distribution and failure patterns of masonry when subjected to blast pressure with more than $100 \mathrm{~ms}$ positive phase duration. A total of ten (10) masonry walls of different geometries were subjected to blast test events with $200 \mathrm{~ms}$ and $150 \mathrm{~ms}$ positive phase durations corresponding to peak over pressures of $55 \mathrm{kpa}$ and $110 \mathrm{kpa}$, respectively. All ten (10) samples exhibited structural failure and it was observed that failure pattern, debris distribution, and initial fragmentation were affected by geometry of walls, overpressure, and impulse of blast loads.

Blast close in contact with structure impinges the structural element such as wall or column before encompassing the whole structure. Local failure changes to global failure due to progressive collapse for poorly designed structural systems.

3.2. Effect of Structural Element Geometries. Structural element length, height, and thickness affect response of the structure to a given blast scenario. Increasing thickness of structural elements improves the performance if other parameters are kept constant. Pandey and Bisht [29] and Pereira et al. [30] reported enhanced dynamic performance with increasing thickness of brick masonry wall against blast loading. Wei and Stewart [31], using LS-DYNA, reported that increasing masonry wall thickness decreases damage level. Increasing aspect ratio (height/thickness) of masonry wall decreases its resistance against blast loading. Parisi et al. [32] reported $116 \%$ increase in resistance against blast loading of tough stone masonry (TSM) when transverse aspect ratio was decreased from 10 to 5 .

3.3. Effect of Material Properties. Response of structure against blast loading varies among structures fabricated from different materials. Wei and Stewart [31], using LS-DYNA, found that increase in strength of mortar and masonry unit results in decrease of maximum deflection in masonry and rotation at support under small blast loading. Pereira et al. [30] studied behavior of $1.7 \mathrm{~m} \times 3.5 \mathrm{~m}$ masonry infill wall on scaled model of $1: 1.5$, subjected to out-of-plane loading using newly developed technique of confined underwater blast wave generators (WBWG) with experimental set-up shown in Figure 5. Parametric study regarding the effect of geometrical and material properties of infill masonry on the performance of masonry was carried out. Increasing compressive and tensile strengths and, modulus of rigidity $G$ of infill masonry up to certain level decreased maximum deflection in the masonry in the region of small scaled 


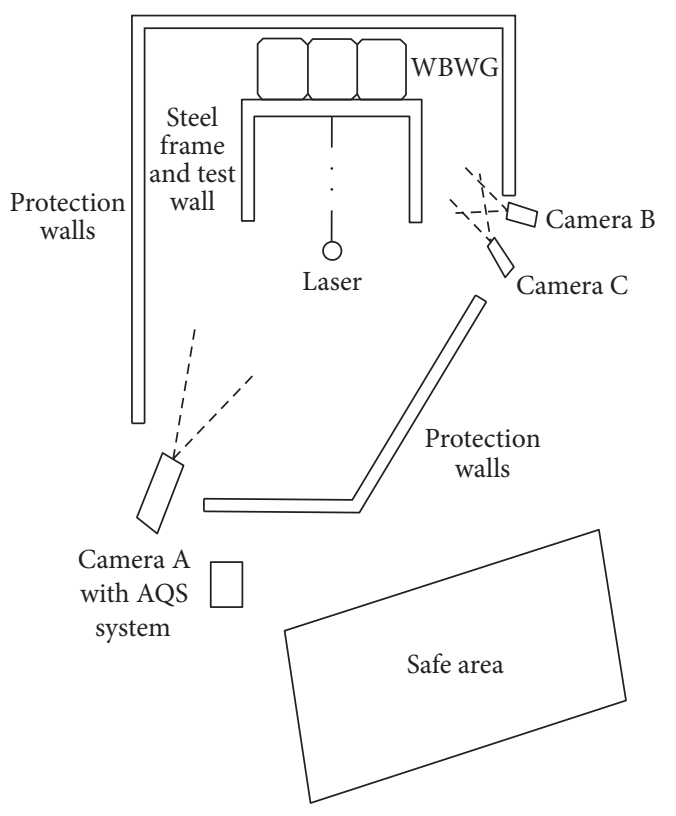

Figure 5: Detail of experimental set-up.

distances. Increasing Young's Modulus E decreased maximum deflection at all scaled distances.

Pandey and Bisht [29] reported that increasing coefficient of friction and richness of mortar used in masonry resulted in decreasing max deflection at the centre as well as at masonry and frame interface against blast loading. Parisi et al. [32] reported significant influence of material strength on resistance of tough tile masonry (TSM) against impulsive and dynamic loading.

3.4. Boundary Conditions and Precompression Ratio. Boundary condition of structural or nonstructural elements plays an important role in structural response and damage level against blast loading. Wei and Stewart [31], using LS-DYNA, studied response of masonry walls with different boundary conditions as shown in Figure 6. Maximum deflection and damage level decreased with inducing increased number of fixed ended conditions. All walls predicted to collapse under larger blast loads when scaled distance is less than or equal to $4.0 \mathrm{~m} / \mathrm{kg}^{1 / 3}$. El-Domiaty et al. [33] reported that changing boundary conditions changes response of brick masonry appreciably; however, modifying boundary conditions especially in infill masonry has its limitations.

$\mathrm{Hao}$ and $\mathrm{Wu}$ [34] and $\mathrm{Wu}$ and Hao [35] found different scaled distances $4.50 \mathrm{~m} / \mathrm{kg}^{1 / 3}$ and $4.22 \mathrm{~m} / \mathrm{kg}^{1 / 3}$, respectively, for the same damage level (nonexcessive damage) in infill masonry with same material model but with different material models of RC frames. Ahmad et al. [36] reported no damage at scaled distance of $2.28 \mathrm{~m} / \mathrm{kg}^{1 / 3}$ of solid clay brick masonry cantilever wall in experimental study but $\mathrm{Wu}$ and Hao [35] found collapse of infilled CMU masonry in RC frame at a higher scaled distance of $2.37 \mathrm{~m} / \mathrm{kg}^{1 / 3}$ in numerical study. Badshah [4] found minor damage and no damage in unconfined and confined clay brick masonry, respectively, for
A

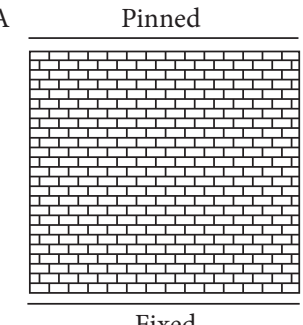

B

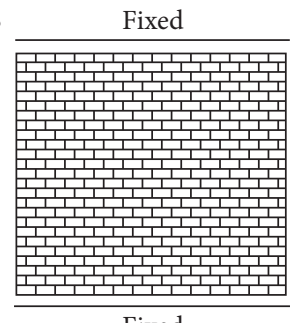

C

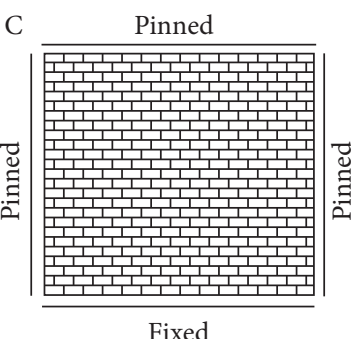

$\mathrm{D}$

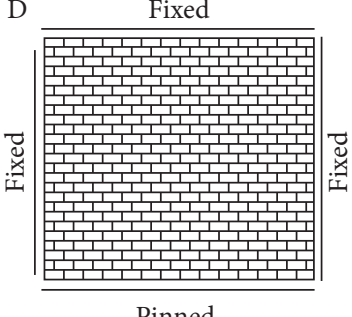

FIGURE 6: Detail of boundary conditions.

the same scaled distance $4.5 \mathrm{~m} / \mathrm{kg}^{1 / 3}$ as shown in Figure 7 . Similarly, for scaled distance $1.89 \mathrm{~m} / \mathrm{kg}^{1 / 3}$, unreinforced wall collapsed completely and confined masonry wall, though damaged, remained intact as shown in Figure 8.

Precompression in load bearing masonry significantly changes response against blast loading. Parisi et al. [32] found an enhanced performance against blast loading of tough tile masonry (TSM) with increasing precompression ratio.

\section{Mitigation}

No single remedy exists against blast loading but combination of the following active and passive techniques shall be employed for effective mitigation:

(i) Initial layer of mitigation against terrorist bombing is the efficient use of intelligence and security agencies for intercepting the suicide bombers and other criminals laden with explosive devices before reaching specified public or private commercial building.

(ii) It is followed by increasing the stand-off distance between point of explosion and targeted buildings by providing physical barriers. Physical barriers in the shape of blast walls attenuate blast wave parameters behind the wall.

(iii) Proper landscape, building orientation, and architectural design with respect to specific blast threat play important attenuating role.

(iv) Building redetailing, capacity design, designed for continuity and use of ductile and energy absorbing yet high strength materials in structure fabrication, and proper retrofitting techniques strengthen the structure when all other techniques fail against blast loading.

Goel et al. [37] reviewed mitigation strategies for mitigation of blast load against buildings. Different blast mitigation 


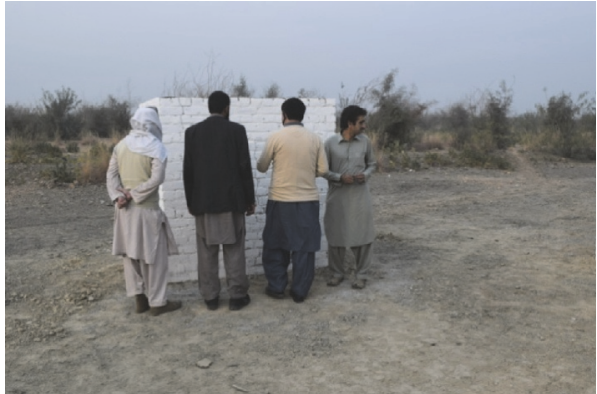

(a)

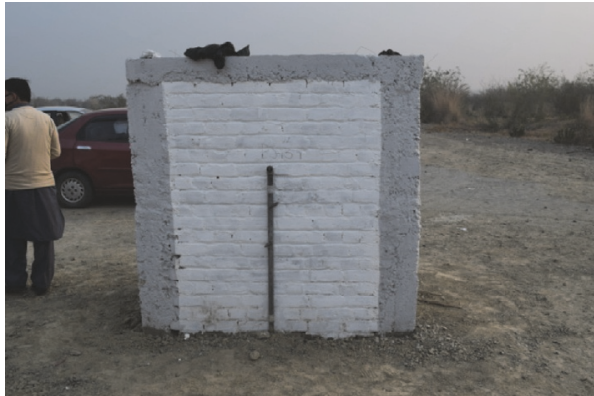

(b)

FIGURE 7: For scaled distance $4.5 \mathrm{~m} / \mathrm{kg}^{1 / 3}$ postblast scenario, (a) unreinforced masonry and (b) confined masonry.

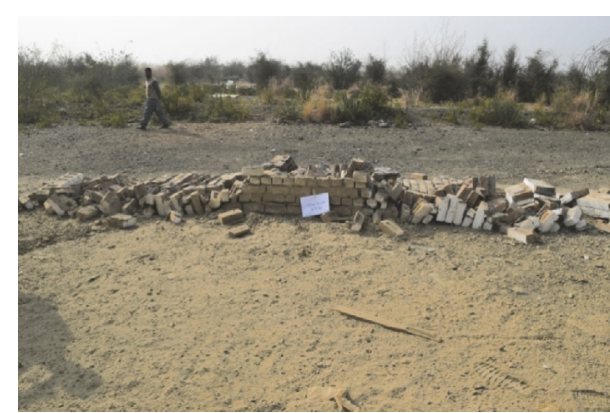

(a)

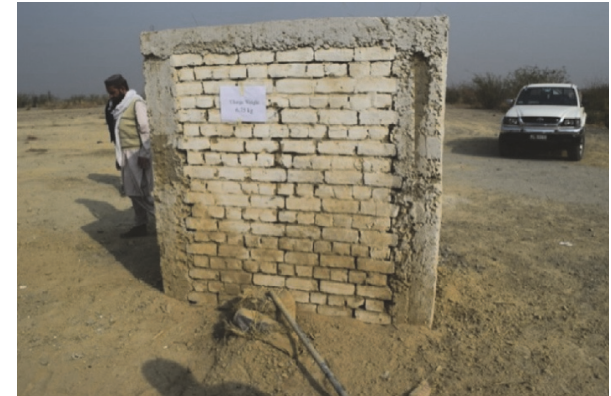

(b)

FIGURE 8: For scaled distance $1.89 \mathrm{~m} / \mathrm{kg}^{1 / 3}$ postblast scenario, (a) unreinforced masonry and (b) confined masonry.

strategies include increasing stand-off distance by construction of barriers, redistribution of mass of structure, shaping building in such way to avoid square-edge, rectangular longedge sections in the path of direct shock waves, using light weight energy absorbing materials (metal and polymeric foams) in fabrication of buildings, and provision of properly designed sacrificial blast walls. Design of blast wall shall result in nonformation of Mach stem behind it.

4.1. Blast Wall. It is a physical barrier used to protect vulnerable buildings and structures along with people inside from the devastating effects of a nearby explosion. Smith and Rose [38] defined blast wall as "a physical barrier separating a valuable asset from explosive threat that produces a blast capable of damaging asset; the wall mitigates the level of blast loading that impinges on the asset being protected."

Beyer [39] visualized the path of the incident wave diffracting over the blast wall as shown in Figure 9 and reported attenuated positive peak overpressure behind the wall.

Chapman et al. [40] incorporated geometrical parameters in finding protection factor as a function of scaled distance in small scale experimental study. Efficiency of blast wall was found dependent on its height, height of explosive above ground surface, height of target, and horizontal stand-off distances from blast wall to target structure and from blast wall to the charge.

Rose et al. [41], developed design charts, incorporating effect of distance from the wall to the target point behind the wall, distance of wall from the charge, and height of blast wall.
Author reported that, in case of rigid wall, the effect of canopy or shape of the canopy as compared to the plan wall on the pressure behind the wall was found insignificant. It was also found that the wall should be close to the point of blast for an early interaction and consequently more attenuation effect.

Zhou and Hao [42] carried out numerical study using AUTODYN3D to estimate surface blast loads on a structure behind the protective barrier or blast wall. The weight of equivalent TNT " $W$," height of building " $H_{B}$," distance between the charge and building " $D$," the height of the blast wall " $H_{1}$," the ratio of distance between the blast wall and explosion to that between the building and the explosion " $L_{1} / D$," and thickness of blast wall were varied between $10 \mathrm{~kg}$ to $1000 \mathrm{~kg}, 3 \mathrm{~m}$ to $40 \mathrm{~m}, 0.2$ to $0.8,1 \mathrm{~m}$ to $40 \mathrm{~m}$, and $150 \mathrm{~mm}$ to $300 \mathrm{~mm}$, respectively, as shown in Figure 10.

Numerical study showed insignificant effects on the pressure parameters behind the protective barrier with the changing of barrier thickness in the range $150 \mathrm{~mm}$ to $300 \mathrm{~mm}$. Therefore, wall thickness was fixed at $250 \mathrm{~mm}$ in each case. Provision of barrier between building and point of explosion decreased positive peak reflected pressure and impulse on the building and arrival time of shock wave was increased. Effects on negative wave parameters were found insignificant. The efficiency of protective wall was found dependent on barrier height, separation of point of explosion and barrier, and distance between the building and barrier structure and height of the structure. Based on the numerical results, models were derived for estimating reflected pressure-time history parameters behind the barrier structure. 


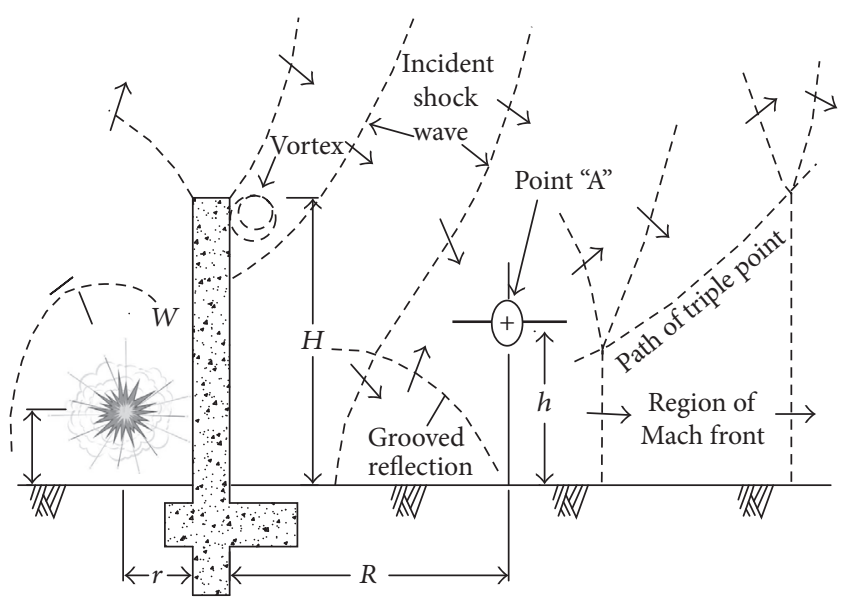

FIGURE 9: Experimental arrangement and visualization pressure waves trajectories diffracting over the blast wall.

Hajek et al. [43] experimentally studied the effect of shape of surface and type of material on performance of barrier wall using $40 \%$ scaled down ratio for the blast wall. Deformable material performance was compared with Ultra High Performance Fiber-Reinforced Self Compacting Concrete (UHPFRSCC). Small rough surface wall produced results comparable with the results attainable by larger smooth surface walls, thereby inducing an added advantage to the former in congested environment. Sheeting with an uneven surface can also be used in structural walls, ceiling, and so forth for reducing the reflected over pressure. The deformable wall showed an increased mitigation in comparison to the rigid wall. UHPFRSCC wall performance was found excellent and recommended its use for internal as well as external applications.

Philip [44] experimentally worked out reduction factors for pressure and impulse behind the barrier wall. These factors were based on slant ranges from top of wall to the top of building and from top of wall to the charge. Research in this field was accelerated in the back drop of terrorist activities in 1970 .

Jones et al. [45] used 1/10th scaled model of blast wall and suitable scaled charge of vehicle born improvised explosive device (VBIED), exploded at varying stand-off distances from embassy building to evaluate its potential against blast loading. Models were developed for overpressure and reflected overpressure impulse with and without perimeter wall (blast wall) shown in equations (17)-(18).

Reflected overpressure and reflected overpressure impulse without perimeter wall (blast wall) are as follows:

$$
\begin{aligned}
& P_{w}=287.0 * Z^{-1.57}, \\
& I_{w}=30.9 * Z^{-0.822} * W^{1 / 3} .
\end{aligned}
$$

Reflected overpressure and reflected overpressure impulse with perimeter wall (blast wall) are as follows:

$$
\begin{aligned}
& P_{w o}=1433.0 * Z^{-2.21}, \\
& I_{w o}=70.9 * Z^{-0.977} * W^{1 / 3} .
\end{aligned}
$$

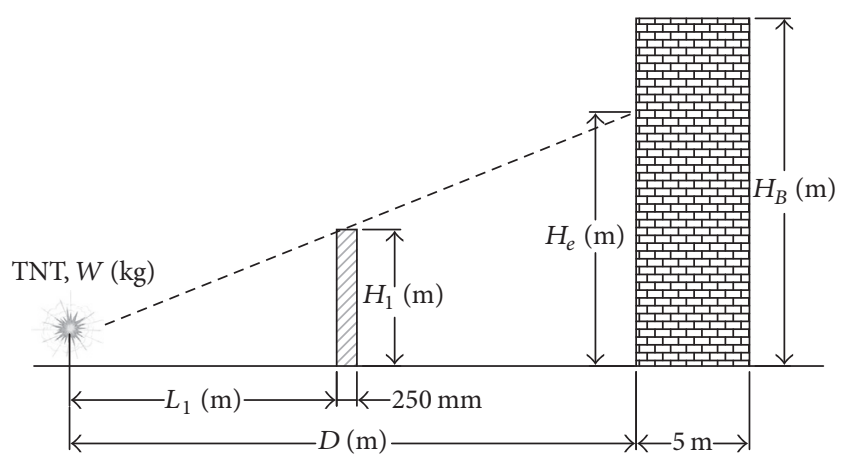

FIGURE 10: Detail of explosive placement, barrier wall, and target building.

Comparison of both scenarios indicates the mitigation capacity of blast wall against blast loading.

Rose et al. [46] used 1/10th scaled model of $3 \mathrm{~m}$ plan tall wall fabricated from steel for affecting the blast on selected points behind the wall. The results with and without barrier wall shown in contour maps indicating reduction in zone of highest pressure are shown in Figure 11.

This study showed that rigid, plane, and robust wall mitigated pressure and impulse significantly up to six times of wall height behind the wall.

Rose et al. [47] studied effect of mass and strength of blast wall on attenuating peak pressure behind the wall. Thick sand wall showed better performance against rigid plan wall as well as walls made of wood, polymer sheets, and ice, as shown in Figure 12.

Bogosian and Piepenburg [48] reported that frangible walls fabricated from light weight concrete masonry unit (CMU), water wall, or thin precast concrete panels reduce the blast effects significantly as shown in Figure 13.

Figure 13 shows that less expensive frangible material walls exhibiting mitigation effects are almost at par with rigid wall.

Mayor and Flanders [49] developed computer software incorporating the models developed by Jones et al. [45] for assessing the effects of vehicle born improvised explosive device (VBIED) on the structure and personnel of US embassies.

Smith and Rose [38] presented research work dealing with blast wall performance in protection against blast loading. Furthermore, different types of blast wall in use were presented.

Properly designed blast walls attenuate blast wave parameters significantly. Consequently, damage to built environment and life is minimized. Choice of particular type of blast is governed by ease of fabrication, transportation, space constraints, economy, and vitality and importance of property to be protected.

4.2. Architectural and Geometrical Aspects of Buildings. Buildings shapes, space, and orientation are usually decided based on environmental consideration, aesthetics, and functionality coupled with available land space and resources. This general practice may not be in consonance with specific 


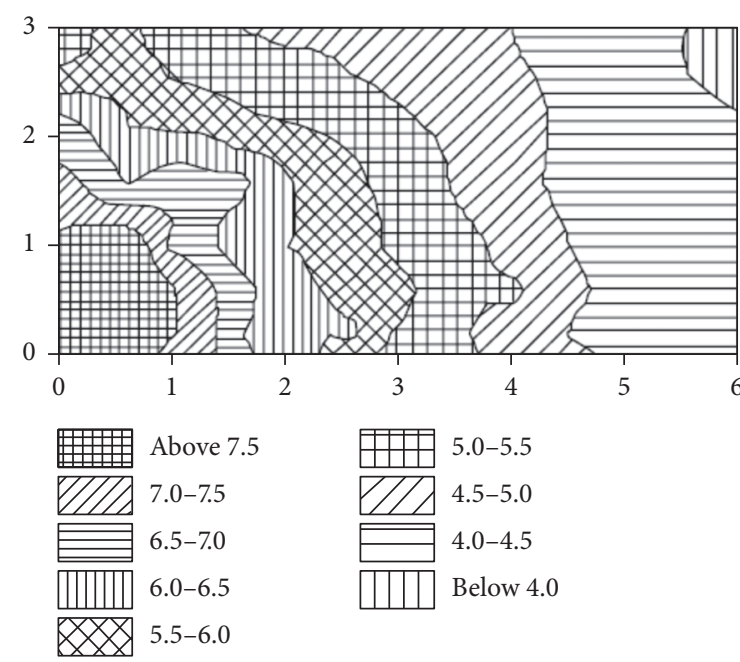

(a)

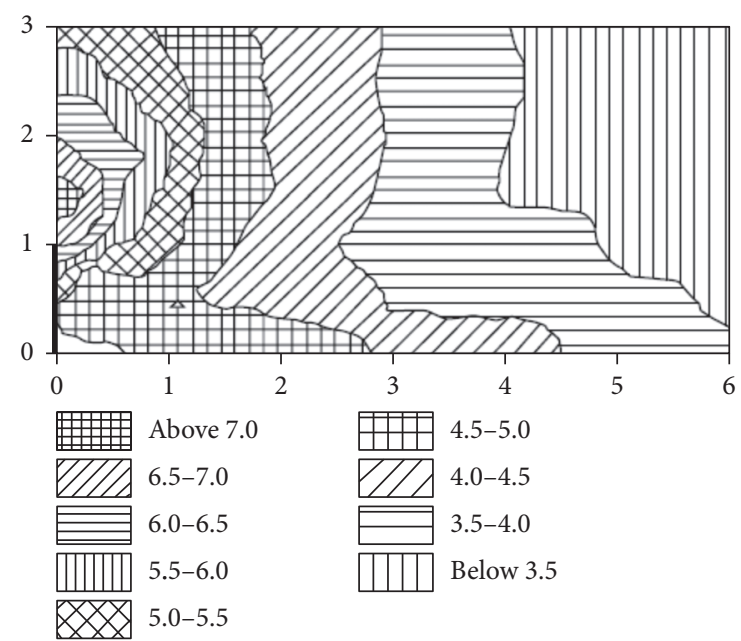

(b)

FIgURE 11: (a) Pressure contour map without wall; (b) pressure contour map with wall.

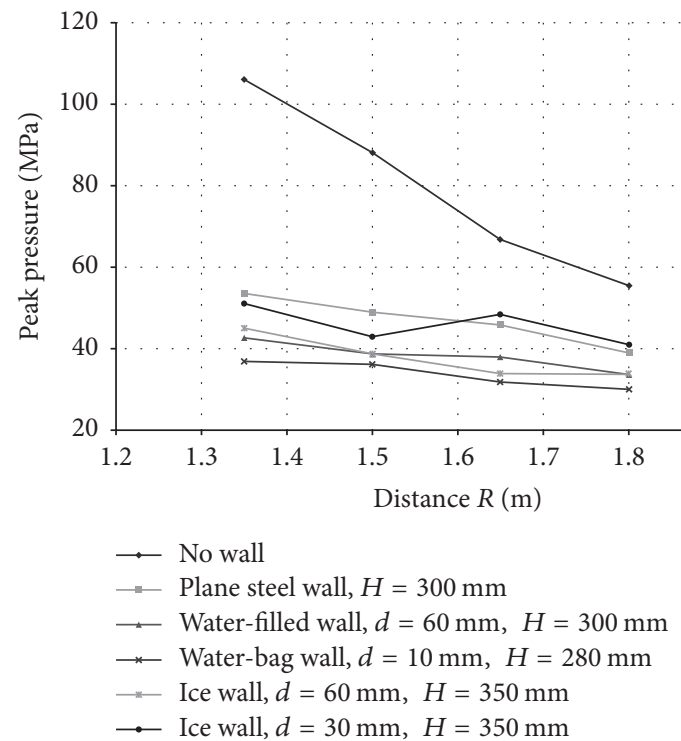

Figure 12: Peak pressure attenuation with different blast wall.

requirements of blast loading. Various researchers investigated blast efficient architectural design of buildings. Koccaz et al. [50] studied incorporation of blast resistant design aspects in both architectural and structural design stages of buildings. Author has reported as much stand-off distance by erection of barriers between external bomb and newly planned and existing buildings as possible and minimum stand-off distance from building shall be 30 meters as shown in Figure 14.

Arches and domes shapes attenuate the effect of blast pressure when compared with cubicle or rectangular shapes. Similarly, complex shape geometry of building causing multiple reflections experiences much loads. Single-storey building and partially or fully embedded building response

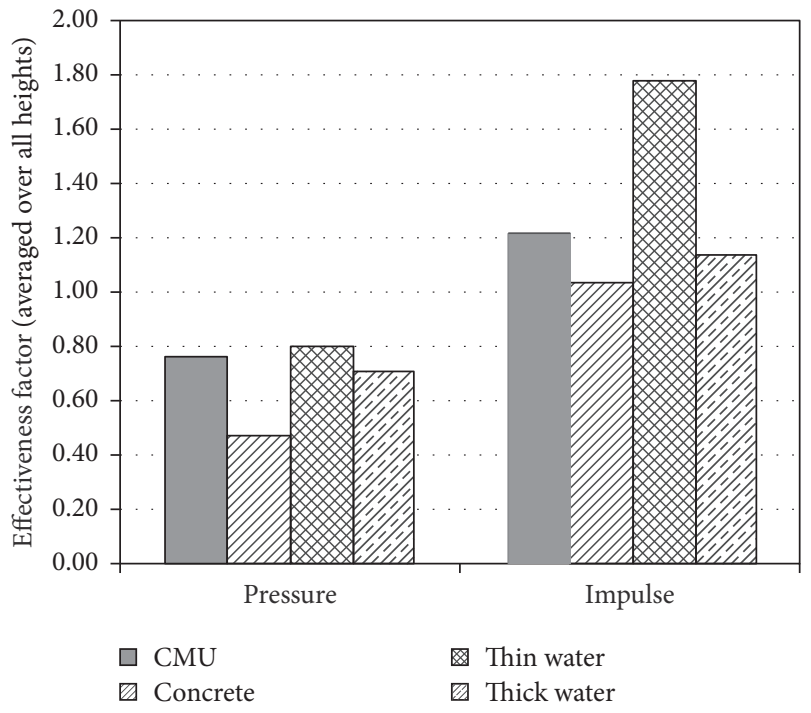

FIGURE 13: Peak pressure and impulse variation with blast wall fabricated from different materials.

are well against blast loading. Sensitive or high value assets in building shall be separated as far as possible from the highest possible threat. Entry points to building shall be separated and strictly controlled. Underground car parking or passage poses risk unless properly checked and controlled. Properly designed shelter areas shall be provided in case of any incident. Building shall be designed to tolerate reversal of loads and avoid progressive collapse. Beam-column joint shall be properly designed against blast induced forces. Barakat and Hetherington [51] found the effects on blast waves and fragments due to landscape. Author mentioned that ground profile technique, as shown in Figure 15, provided shielding effect to the building.

Barakat and Hetherington [52] introduced blast efficient architectural forms after evaluating efficiency of various 


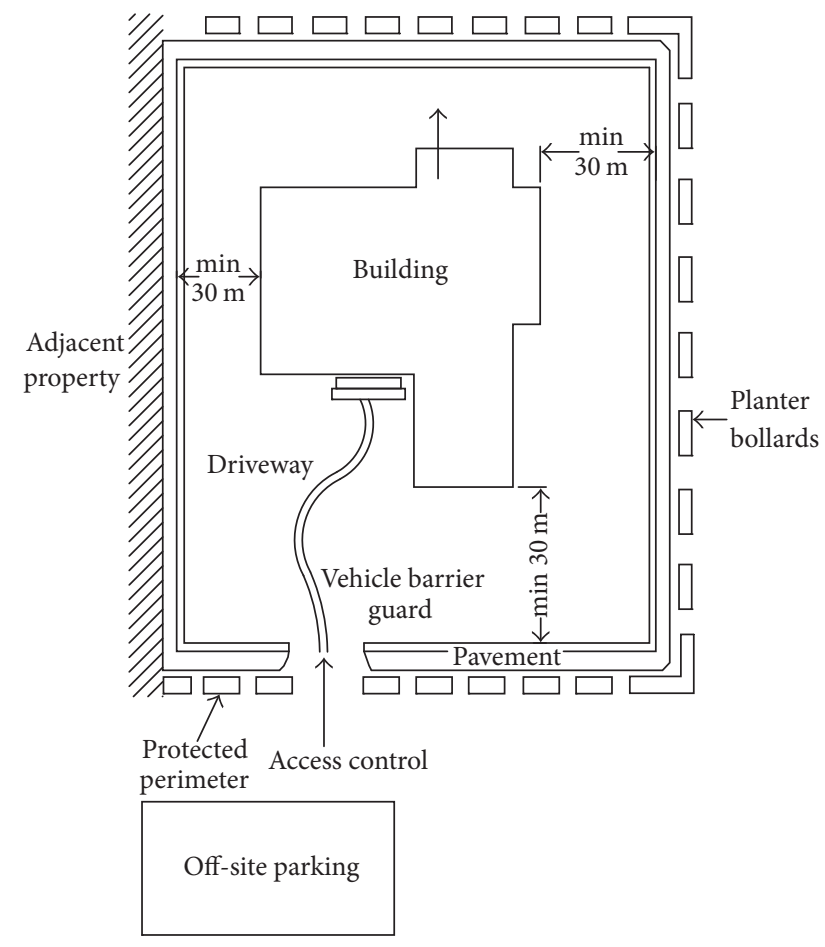

FIGURE 14: Layout of building for blast protection.

structural shapes subjected to car bomb threat scenario at $15 \mathrm{~m}$ stand-off distance by using simulations in AUTODYN. Decrease in impulse with height was found more when the corner or apex of the plan structure was positioned towards the explosion. In wing-form-plan structure with obtuse angle between the two wings more decrease in impulse with height was found. Significant decrease in impulse in hemispherical structure was observed. Similarly, stepped form architecture and introvert design manifested relief in the impulse. Gebbeken and Döge [53] discussed different strategies for protecting buildings in urban environment against blast loadings. Properly designed nonconvex shape, planting hedges in landscape, use of soft and energy absorbing material in facades, selecting circular sections for structural elements, and increasing stand-off distance attenuate the blast wave parameters. Gunaratan, [54] narrated that truck loaded explosive caused enormous devastation in Mariot Hotel Islamabad Pakistan despite greater standoff distance of $40.23 \mathrm{~m}$ against standard practice distance of $30.50 \mathrm{~m}$ between the gate and main building. Kulkarni and Sambireddy [55] reported that maximum storey drift in regular frame was found less than the irregular frame for the same loading scenario. Infill frame performed well in storey drift against lateral blast loading. Consequently, regular infill frame was found most efficient in blast loading.

4.3. Retrofitting Techniques. Building may be strengthened against blast loading by using different retrofitting techniques. Knox et al. [56] and El-Domiaty et al. [33] reported different techniques for enhancing response of unreinforced brick masonry against blast loading such as increasing wall thickness, changing boundary conditions, replacement of weak elements, and incorporating steel reinforcement. All these techniques are expensive, impractical, and timeconsuming in most of the situations. Therefore, new techniques which are easier, light weight, and less expensive such as FRP (CFRP, GFRP, and AFRP), polyurea, polyurethane, aluminum foam, engineered cementitious composites, and ferrocement are used. These techniques are used for increasing ductility as well as arresting dangerous high velocity debris discharging from the target structure or building during blast loading.

4.3.1. FRP. Fiber reinforced polymers (FRP) are unidirectional fabric composites in matrix which are attached to masonry surface by using proper resin or epoxy. FRP strengthened masonry has been extensively investigated (Lantz et al. [57]).

Urgessa and Maji [58] studied, experimentally, the Dynamic Response of Masonry Walls reinforced with carbon fibers using two different matrices against blast loading. Eight masonry walls $101.5 \mathrm{~cm} \times 304.8 \mathrm{~cm} \times 20.4 \mathrm{~cm}$ were fabricated in a circular arrangement inside reinforced concrete containment structure. These walls were retrofitted with unidirectional two layered and four layered FRP by using inorganic matrix geopolymer and organic matrix thixotropic epoxy resin coupled with $2: 1$ hardener separately to four walls each. The FRPs were fastened to the boundaries by use of suitable angle irons. The walls were subjected to blast wave parameters generated from explosive of $0.64 \mathrm{~kg}$ TNT equivalent weight suspended from the roof of test structure in the geometrical centre of experimental arrangement of walls. The displacement response of two layered FRPs walls had little correlation with the type of matrix used. The carbon fibers in four layered walls were able to contain the fragmentation. Retrofit Design procedure was proposed for analysis and design of masonry walls strengthened with FRPs against blast loading. Numerical algorithm of nonlinear SDOF was run for the masonry walls with assumed number of retrofits of FRPs with known tensile strength, modulus of elasticity, and percent elongation. If the peak deflection value taken from displacement time history of the numerical model exceeds the displacement limit, the number of layers of FRPs is reconsidered.

El-Domiaty et al. [33] carried out experimental and numerical studies for assessing the feasibility of Fiber Reinforced Polymers (FRP) as reinforcing technique for unreinforced brick masonry against blast loading. The damage levels in these were coupled with charge weight and stand-off distance. Pressure transducers and accelerometers were installed on the test specimen for recording pressure and acceleration time histories.

The response of different walls demonstrated enhanced capacity of FRP retrofitted walls against more threat levels. FRP strengthened walls failed in safe manner avoiding dangerous scattering of fragments while the unreinforced masonry wall failed in abrupt flexure mode splashing debris. Single Degree of Freedom System Analysis was successfully used for predicting the response of FRP reinforced masonry wall. Similarly, comparing the test results with TM 5-1300 Code etc requirements, support rotations and ductility ratio 


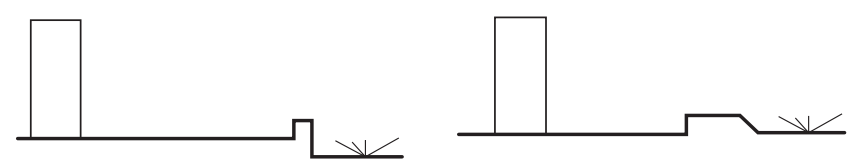

FIGURE 15: Landscape design for attenuating blast effect.

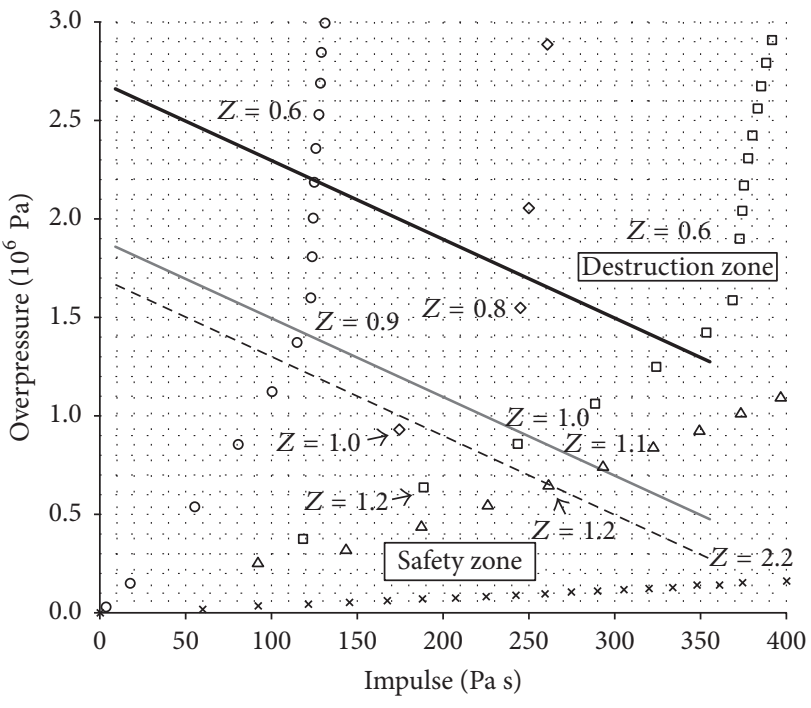

- - - Nonreinforced CMU wall $P=-0.004 I+1.7$

Welded mesh reinforcement for CMU wall $P=-0.004 I+1.9$

- Composite fabric reinforcement for CMU wall $P=-0.004 I+2.5$

FIGURE 16: Resistance of CMU for different system of reinforcement.

guidelines were suggested for retrofitting of masonry with RFP.

Sielicki [59], in Ph.D. thesis, elaborated the failure of masonry subjected to impulse loading. The researcher obtained the highest safety threshold by application of composite fabric reinforcement to concrete masonry wall as shown in $P$-I curves in Figure 16.

Similarly, Tan and Patoary [60], Baylot et al. [61], Stanley et al. [62], Stratford et al. [63], Alsayed et al. [64], Bui and Limam [65], Chen et al. [66], Hamed and Rabinovitch [67], Hamed and Rabinovitch [68], and Haderi et al. [69] investigated and reported increased performance of FRP strengthened masonry walls.

According to Buchan and Chen [70], extensive experimental and numerical studies have shown benefits of FRP and Polymer retrofitting in increasing structural strength and ductility of structure along with reducing the danger of shrapnel. Blast loading and response problems is complex in nature, involving so many variables, lacking vital information regarding exact charge weight and stand-off distances and designs guidelines for practical applications cannot be established on the basis of experiments only. Consequently, studies conducted so far are not quantitative in nature and explicit guidelines for application of FRP to large structures are still wanting.
4.3.2. Polyurea. It is cross-linked amorphous monomer or polyamine and prepolymer, essentially containing at least $80 \%$ polyamine (Tekalur et al. [71]). Water, chemical, and abrasion resistant elastomeric material used in retrofitting of masonry structures.

Knox et al. [56] reported successful arresting of fragments when elastomeric polymer (polyurea) coated with concrete block walls was subjected to $0.55 \mathrm{MPa}$ blast pressure. Wang et al. [72] experimentally studied failure mechanism, modes, and peak pressure for damage of clay brick masonry and aerated concrete block walls strengthened with polyurea with different boundary conditions subjected to blast loading. The damage in clay brick masonry wall started at the joints and extended from top to bottom at the centre of wall and deformation is less pronounced. In aerated concrete block walls, greater cracks were found in mortar and deformation observed were significant. Polyurea-sprayed walls exhibited enhanced performance against blast loading and flexural strength was improved and mortar joint damage was localized. The performance of clay brick masonry wall exceeded the aerated concrete block masonry wall in both unreinforced and reinforced scenario. The structural collapse of walls was avoided and fatal fragments were arrested. After application of polyurea, the ultimate blast resistance of clay brick masonry and aerated concrete block masonry was increased by factors $4.5-11$ and 15 , respectively.

Similarly, Johnson et al. [73], Davidson et al. [74], Davidson et al. [75], Baylot et al. [61], Irshidat et al. [76], Haderi et al. [69], and Aghdamy et al. [77] reported enhanced performance of polyurea treated masonry against blast loading.

4.3.3. Aluminium Foam. An early start of plastic deformation, high strength, and corrosion resistance of aluminum foam makes it suitable for retrofitting masonry structures (Lantz et al. [57]). Su et al. [78] and Aghdamy et al. [77] investigated performance of aluminium foam by conducting FEA-analysis using LS-DYNA and found its potentiality to be used as retrofitting material.

4.3.4. Engineered Cementitious Composites. It is micromechanically designed material, molded mortar-based composite reinforced with specially selected short random fibers, usually polymer fibers, and was invented in early $90 \mathrm{~s}(\mathrm{Li}$ [79]). Maalej et al. [80] reported increased resistance of engineered cementitious composites and recommended its use for increasing masonry wall resistance against blast loading.

4.3.5. Ferrocement. It has been widely used in masonry structures for mitigation against seismic loading. Badshah [4], 


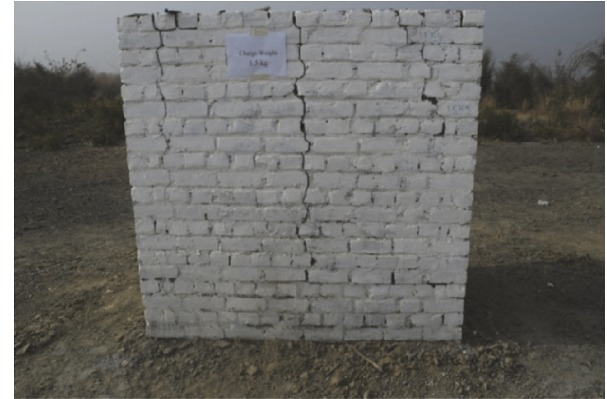

(a)

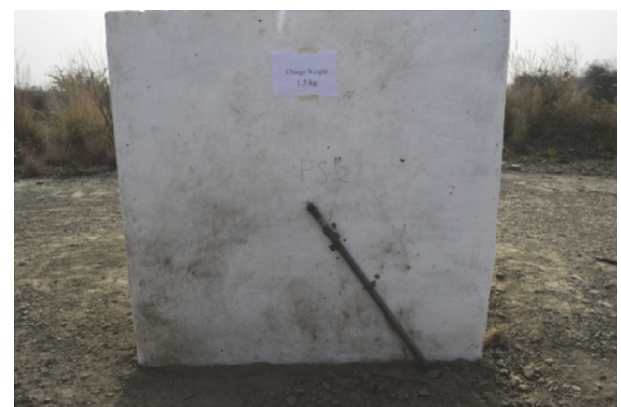

(b)

FIGURE 17: (a) Major shear and flexural cracks in unreinforced masonry wall and (b) no damage ferrocement wall.

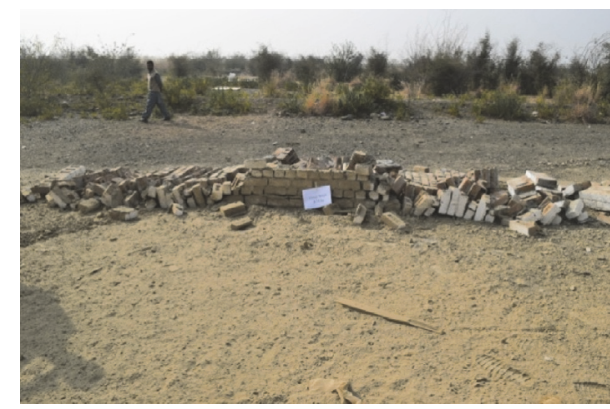

(a)

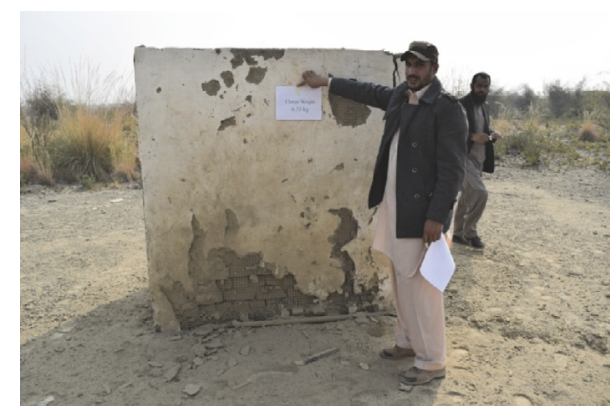

(b)

FIGURE 18: (a) Collapse of unreinforced masonry wall and (b) partially damaged but intact ferrocement wall.

in his Ph.D. experimental work, found an enhanced performance of ferrocement clay brick masonry in comparison to unreinforced masonry wall against blast loading. Geometrical and material models of both walls were kept constant. Unreinforced wall showed major diagonal (shear) and central (flexural) cracks at measured peak reflected pressure of $0.205 \mathrm{MPa}$ while ferrocement wall experienced no damage as shown in Figure 17. Similarly, unreinforced masonry wall collapsed and ferrocement wall, though partially damaged, remained intact when subjected to same peak positive reflected pressure of magnitude $1.01 \mathrm{MPa}$ as shown in Figure 18. This technique is relatively simple, is less costly, and requires no special skill during fabrication.

All the above techniques incorporate ductility and strength to the masonry walls. Furthermore, high velocity debris ejected are confined and injuries are minimized.

\section{Conclusions}

(1) Most of blast load empirical models are either for free air burst or surface burst. Free air burst and surface burst empirical models proposed by different researchers for peak over pressure show large variation especially in the region of small scaled distance. Further research is required for predicting accurate shock wave parameters in the region very close to the centre of explosion.

(2) Ground conditions (sandy, clayey, gravel, loose, compacted, consolidated, rock, concrete, and RCC pavement) shall be incorporated in the prediction models. Similarly, empirical models are oversimplified and do not take the complex interaction of shock waves with the target structure and surrounding built environment. Therefore, numerical methods based on computational fluid dynamics (CFD) may be used for finding more accurate blast wave parameters and evaluating response of structure in urban environment.

(3) Different researchers have studied individual structural elements such as reduced scale wall, column, and slab. The response of complete masonry building shall be studied. Most of the research work has been devoted to concrete block masonry. Clay brick masonry is a major structural and infill material in many regions. Therefore, response of clay brick masonry against blast loading shall be studied.

(4) Damage to structure can be confined to certain level either by attenuating blast load parameters before reaching the target or redetailing and retrofitting of structural elements, proper landscaping, and incorporating blast load efficient architecture. In important buildings where space is not expensive, proper landscaping and blast efficient architectural design can play important role in blast mitigation.

(5) Retrofitting techniques using FRP and polyurea have been proved efficient in blast mitigation. Retrofitting techniques to masonry have been applied and investigated in the preblast scenario. Efficiency of retrofitting techniques in the damaged masonry buildings in the postblast scenario shall be investigated and evaluated. FRP retrofitting techniques are quite efficient in increasing the ductility of structure 
and arresting the flying debris but fail in debonding usually at the supports and need further investigation and design guidelines.

(6) Low cost techniques such as ferrocement have been proven efficient against earthquake loads and also manifested its potential against blast loads. Ferrocement gives smooth plastered surface and further surface treatment and ensuing cost can be avoided. Furthermore, main constituents of ferrocement are mortar and steel mesh, screw, and rowel plug which are indigenously available in most of the blast prone regions. Therefore, it requires further investigation as strengthening technique in pre- and postblast scenarios.

\section{Notations}

TNT: Trinitrotoluene

$Z$ : $\quad$ Scaled distance, $\mathrm{m} / \mathrm{kg}^{1 / 3}$

$W: \quad$ TNT equivalent weight, $\mathrm{Kg}$

$R: \quad$ Scaled distance, $\mathrm{M}$

$P_{o}: \quad$ Standard atmospheric pressure, $\mathrm{Pa}$

$P_{\text {pos }}:$ Peak positive incident overpressure, $\mathrm{Pa}$

$P_{r}: \quad$ Peak positive reflected pressure, $\mathrm{Pa}$

$P_{s o}{ }^{-}$: Peak negative pressure, $\mathrm{Pa}$

$t_{A}:$ Time of arrival of shock waves, $\mathrm{S}$

$t_{o}: \quad$ Positive phase duration, $\mathrm{S}$

$t_{o}{ }^{-}:$Negative phase duration, $S$

$i_{s}: \quad$ Positive specific impulse, $\mathrm{s} \cdot \mathrm{Pa}$

$i_{s}^{-}: \quad$ Negative specific impulse, $s \cdot P a$.

\section{Conflicts of Interest}

The authors declare that there are no conflicts of interest regarding the publication of this paper.

\section{References}

[1] Unified Facilities Criteria (UFC) 3-340-02, Structures to Resist the Effects of Accidental Explosions, Department of Defense, Washington, DC, USA, 2008.

[2] V. Karlos, G. Solomos, and M. Larcher, "Analysis of the blast wave decay coefficient using the Kingery-Bulmash data," International Journal of Protective Structures, vol. 7, no. 3, pp. 409429, 2016.

[3] A. Ullah, F. Ahmad, H.-W. Jang, S.-W. Kim, and J.-W. Hong, "Review of analytical and empirical estimations for incident blast pressure," KSCE Journal of Civil Engineering, pp. 1-15, 2016.

[4] E. Badshah, Performance evaluation of clay brick masonry against blast loading [Ph.D. thesis], University of Engineering Technology (UET) Peshawar Pakistan, 2017.

[5] H. L. Brode, "Numerical solutions of spherical blast waves," Journal of Applied Physics, vol. 26, no. 6, pp. 766-775, 1955.

[6] J. Henrych and R. Major, The Dynamics of Explosion and its Use, Elsevier Scientific, Amsterdam, Netherlands, 1979.

[7] M. Held, "Blast waves in free air," Propellants, Explosives, Pyrotechnics, vol. 8, no. 1, pp. 1-7, 1983.

[8] G. F. Kinney and K. J. Graham, Explosive Shocks in Air, Springer Science \& Business Media, 2013.

[9] C. A. Mills, "The design of concrete structure to resist explosions and weapon effects," in Proceedings of the 1st International Conference on concrete for hazard protections, pp. 61-73, September 1987.
[10] M. A. Sadovskiy, "Mechanical effects of air shockwaves from explosions according to experiments," in Sadovskiy MA Selected Works: Geophysics and Physics of Explosion, Nauka Press, Moscow, Russia, 2004.

[11] Z. Bajić, Determination of TNT equivalent for various explosives [M.S. thesis], University of Belgrade, Belgrade, Serbia, 2007.

[12] US Army, Fundamentals of Protective Design (Non-Nuclear), Department of Army Technical Manual, TM5-855-1, US Army, Washington, DC, USA, 1965.

[13] N. M. Newmark and R. J. Hansen, "Design of blast resistant structures," in Shock and vibration handbook 3, 1961.

[14] M. M. Swisdak Jr., Simplified Kingery Airblast Calculations, Naval Surface Warfare Center, Indian Head, Md, USA, 1994.

[15] C. Wu and H. Hao, "Modeling of simultaneous ground shock and airblast pressure on nearby structures from surface explosions," International Journal of Impact Engineering, vol. 31, no. 6, pp. 699-717, 2005.

[16] J. I. Siddiqui and S. Ahmad, "Impulsive loading on a concrete structure," Proceedings of the Institution of Civil Engineers: Structures and Buildings, vol. 160, no. 4, pp. 231-241, 2007.

[17] S. Ahmad, A. Elahi, J. Iqbal, M. A. Keyani, and A. G. A. Rahman, "Impulsive loading on reinforced concrete wall," Proceedings of the Institution of Civil Engineers: Structures and Buildings, vol. 166 , no. 3, pp. 153-162, 2013.

[18] J. Iqbal and S. Ahmad, "Improving safety provisions of structural design of containment against external explosion," in Proceedings of International conference on opportunities and challenges for water cooled reactors in the 21st century, Intenational Atomic Energy Agency (IAEA), 2011.

[19] P. D. Smith and T. A. Rose, "Blast wave propagation in city streets-an overview," Progress in Structural Engineering and Materials, vol. 8, no. 1, pp. 16-28, 2006.

[20] Birnbaum, K. Naury, A. Richard, E. F. Gerg, J. H. Colin, and J. F. Nigel, "Analysis of blast loads on buildings", in Preprint from Structures under Extreme Loading Conditions, 1996.

[21] M. Johansson, O. P. Larsen, L. Laine, and REINERTSEN Sverige AB, "Explosion at an intersection in an Urban Environment-Experiments and analyses," in Proceedings of the 78th Shock and Vibration Symposium, Philadelphia, PA, USA, 2007.

[22] A. M. Remennikov, "Evaluation of blast loads on buildings in urban environment," WIT Transactions on The Built Environment, vol. 73, 2004.

[23] T. A. Rose and P. D. Smith, "Influence of the principal geometrical parameters of straight city streets on positive and negative phase blast wave impulses," International Journal of Impact Engineering, vol. 27, no. 4, pp. 359-376, 2002.

[24] G. C. Mays and P. D. Smith, Blast Effects on Buildings: Design of Buildings to Optimize Resistance to Blast Loading, Thomas Telford, 1995.

[25] Design of Concrete Masonry Walls for Blast loading, TEK 1421A. National Concrete Masonry Association, 2014.

[26] T. Ngo, P. Mendis, A. Gupta, and J. Ramsay, "Blast loading and blast effects on structures - an overview," Electronic Journal of Structural Engineering, vol. 3, atricle 5, 2007.

[27] Y. Shi, W. Xiong, Z.-X. Li, and Q. Xu, "Experimental studies on the local damage and fragments of unreinforced masonry walls under close-in explosions," International Journal of Impact Engineering, vol. 90, pp. 122-131, 2016.

[28] R. A. Keys and S. K. Clubley, "Experimental analysis of debris distribution of masonry panels subjected to long duration blast loading," Engineering Structures, vol. 130, pp. 229-241, 2017. 
[29] A. Pandey and R. Bisht, "Numerical modelling of infilled clay brick masonry under blast loading," Advances in Structural Engineering, vol. 17, no. 4, pp. 591-606, 2014.

[30] J. M. Pereira, J. Campos, and P. B. Lourenço, "Experimental study on masonry infill walls under blast loading," in Proceedings of the 9th International Masonry Conference, pp. 1-9, 2014.

[31] X. Wei and M. G. Stewart, "Model validation and parametric study on the blast response of unreinforced brick masonry walls," International Journal of Impact Engineering, vol. 37, no. 11, pp. 1150-1159, 2010.

[32] F. Parisi, C. Balestrieri, and D. Asprone, "Blast resistance of tuff stone masonry walls," Engineering Structures, vol. 113, pp. 233244, 2016.

[33] K. A. El-Domiaty, J. J. Myers, and A. Belarbi, "Blast Resistance of UnReinforced Masonry Walls Retrofitted with Fiber Reinforced Polymers," Center for Infrastructure Engineering Studies Report 02-28, University of Missouri, Rolla, Missouri, 2002.

[34] H. Hao and C. Wu, "Numerical simulation of damage of lowrise RC frame structures with infilled masonry walls to explosive loads," Australian Journal of Structural Engineering, vol. 7, no. 1, pp. 13-22, 2006.

[35] C. Wu and H. Hao, "Safe scaled distance for masonry infilled RC frame structures subjected to airblast loads," Journal of Performance of Constructed Facilities, vol. 21, no. 6, pp. 422-431, 2007.

[36] S. Ahmad, A. Elahi, H. Pervaiz, A. G. A. Rahman, and S. Barbhuiya, "Experimental study of masonry wall exposed to blast loading," Materiales de Construccion, vol. 64, no. 313, 2014.

[37] M. D. Goel, V. A. Matsagar, A. K. Gupta, and S. Marburg, "An abridged review of blast wave parameters," Defence Science Journal, vol. 62, no. 5, pp. 300-306, 2012.

[38] P. D. Smith and T. A. Rose, "Blast wave propagation in city streets - an overview," Progress in Structural Engineering and Materials, vol. 8, no. 1, pp. 16-28, 2006.

[39] M. E. Beyer, Blast Loads behind Vertical Walls, Naval civil engineering lab port hueneme, Port Hueneme, CA, USA, 1986.

[40] T. C. Chapman, T. A. Rose, and P. D. Smith, "Reflected blast wave resultants behind cantilever walls: a new prediction technique," International Journal of Impact Engineering, vol. 16, no. 3, pp. 397-403, 1995.

[41] T. A. Rose, P. D. Smith, and G. C. Mays, "Design charts relating to protection of structures against air blast from high explosives," Proceedings of the Institution of Civil Engineers Structures and Buildings, vol. 122, no. 2, pp. 186-192.

[42] X. Q. Zhou and H. Hao, "Prediction of airblast loads on structures behind a protective barrier," International Journal of Impact Engineering, vol. 35, no. 5, pp. 363-375, 2008.

[43] R. Hajek, M. Foglar, and J. Fladr, "Influence of barrier material and barrier shape on blast wave mitigation," Construction and Building Materials, vol. 120, pp. 54-64, 2016.

[44] E. B. Philip, The Passage of a Blast over a Wall, Ministry of Home Security, 1942.

[45] P. S. Jones, K. P. Vitaya-Udom, and J. M. Watt Jr., "Design of Structures to resist terrorist attack;1/10th scale model perimeter wall tests," Tech. Rep. SL-87-13, US Army Waterways Experiment Station, Structures Laboratory, Vicksburg, MS, USA, 1987.

[46] T. A. Rose, P. D. Smith, and G. C. Mays, "Effectiveness of walls designed for the protection of structures against airblast from high explosives," Proceedings of the Institution of Civil Engineers: Structures and Buildings, vol. 110, no. 1, pp. 78-85, 1995.
[47] T. A. Rose, P. D. Smith, and G. C. Mays, "Protection of structures against airblast using barriers of limited robustness," Proceedings of the Institution of Civil Engineers. Structures and buildings, vol. 128, no. 2, pp. 167-176, 1998.

[48] D. Bogosian and D. Piepenburg, "Effectiveness of frangible barriers for blast shielding," in Proceedings of the 17th International Symposium on the Military Aspects of Blast and Shock, pp. 1-11, 2002.

[49] R. P. Mayor and R. Flanders, Technical Manual-Simplified computer model of air blast effects on building walls, Dept of Transportation, Research and Special Programs Administration, Transportation System Center, Vehicle Crashworthiness Division, Safety and Security System Division, Kendall Square, Cambridge, MA, USA, 1990.

[50] Z. Koccaz, F. Sutcu, and N. Torunbalci, "Architectural and Structural Design for Blast Resistant Buildings," in Proceedings of the 14th World Conference on Earthquake Engineering, Beijing, China, October 2008.

[51] M. Barakat and J. G. Hetherington, "New architectural forms to reduce the effects of blast waves and fragments on structures," in WIT Transactions on The Built Environment, vol. 35, 1970.

[52] M. A. Barakat and J. G. Hetherington, "Architectural approach to reducing blast effects on structures," Proceedings of the Institution of Civil Engineers: Structures and Buildings, vol. 134, no. 4, pp. 333-343, 1999.

[53] N. Gebbeken and T. Döge, "Explosion protection - Architectural design, urban planning and landscape planning," International Journal of Protective Structures, vol. 1, no. 1, pp. 1-22, 2010.

[54] R. Gunaratan, Case Study: The Islamabad Marriott in Flames: Attack on the World's Most Protected Hotel, International Centre for Political Violence and Terrorism Research (ICPVTR), 2008.

[55] A. V. Kulkarni and G. Sambireddy, "Analysis of Blast Loading Effect on High Rise Buildings," Civil and Environmental Research, vol. 6, no. 10, 2014.

[56] K. J. Knox, M. I. Hammons, T. T. Lewis, and J. R. Porter, Polymer Materials for Structural Retrofit, Force Protection Branch, Air Expeditionary Forces Technology Division, Air Force Research Laboratory, Tyndall AFB, Panama, Fla, USA, 2000.

[57] L. Lantz, J. Maynez, W. Cook, and C. M. D. Wilson, "Blast protection of unreinforced masonry walls: a state-of-the-art review," Advances in Civil Engineering, vol. 2016, Article ID 8958429, 11 pages, 2016.

[58] G. S. Urgessa and A. K. Maji, "Dynamic response of retrofitted masonry walls for blast loading," Journal of Engineering Mechanics, vol. 136, no. 7, Article ID 008007QEM, pp. 858-864, 2010.

[59] P. W. Sielicki, "Masonry failure under unusual impulse loading," Wydawnictwo Politechniki PoznaĹ, skiej, 2013.

[60] K. H. Tan and M. K. H. Patoary, "Blast resistance of FRPstrengthened masonry walls. I: approximate analysis and field explosion tests," Journal of Composites for Construction, vol. 13, no. 5, pp. 422-430, 2009.

[61] J. T. Baylot, B. Bullock, T. R. Slawson, and S. C. Woodson, "Blast response of lightly attached concrete masonry unit walls," Journal of Structural Engineering, vol. 131, no. 8, pp. 1186-1193, 2005.

[62] M. Stanley, J. Metzger, R. Martinez, and J. Koenig, UL-like testing of commercial off-the-shelf products that enhance the blast and ballistic resistance of structures, quick look Report 2, New Mexico Tech, Energetic Materials Research and Testing Center, Karagozian \& Case, Burbank, CA, USA, 2005. 
[63] T. Stratford, G. Pascale, O. Manfroni, and B. Bonfiglioli, "Shear strengthening masonry panels with sheet glass-fiber reinforced polymer," Journal of Composites for Construction, vol. 8, no. 5, pp. 434-443, 2004.

[64] S. H. Alsayed, H. M. Elsanadedy, Z. M. Al-Zaheri, Y. A. AlSalloum, and H. Abbas, "Blast response of GFRP-strengthened infill masonry walls," Construction and Building Materials, vol. 115, pp. 438-451, 2016.

[65] T. T. Bui and A. Limam, "Out-of-plane behaviour of hollow concrete block masonry walls unstrengthened and strengthened with CFRP composite," Composites Part B: Engineering, vol. 67, pp. 527-542, 2014.

[66] L. Chen, Q. Fang, J. Fan, Y. Zhang, H. Hao, and J. Liu, "Responses of masonry infill walls retrofitted with CFRP, steel wire mesh and laminated bars to blast loadings," Advances in Structural Engineering, vol. 17, no. 6, pp. 817-836, 2014.

[67] E. Hamed and O. Rabinovitch, "Failure characteristics of FRPstrengthened masonry walls under out-of-plane loads," Engineering Structures, vol. 32, no. 8, pp. 2134-2145, 2010.

[68] E. Hamed and O. Rabinovitch, "Out-of-plane behavior of unreinforced masonry walls strengthened with FRP strips," Composites Science and Technology, vol. 67, no. 3-4, pp. 489-500, 2007.

[69] M. Haderi, V. A. Maleki, and K. Andalibi, "Retrofitting of unreinforced masonry walls under blast loading by FRP and spray on polyurea," Cumhuriyet Science Journal, vol. 36, no. 4, pp. 462477, 2015.

[70] P. A. Buchan and J. F. Chen, "Blast resistance of FRP composites and polymer strengthened concrete and masonry structures-a state-of-the-art review," Composites Part B: Engineering, vol. 38, no. 5-6, pp. 509-522, 2007.

[71] S. A. Tekalur, A. Shukla, and K. Shivakumar, "Blast resistance of polyurea based layered composite materials," Composite Structures, vol. 84, no. 3, pp. 271-281, 2008.

[72] J. Wang, H. Ren, X. Wu, and C. Cai, "Blast response of polymerretrofitted masonry unit walls," Composites Part B: Engineering, 2016.

[73] C. F. Johnson, T. R. Slawson, T. K. Cummins, and J. L. Davis, Concrete Masonry Unit Walls Retrofitted with Elastomeric Systems for Blast Loads, Engineer Research And Development Center Vicksburg Ms, 2004.

[74] J. S. Davidson, J. R. Porter, R. J. Dinan, M. I. Hammons, and J. D. Connell, "Explosive testing of polymer retrofit masonry walls," Journal of Performance of Constructed Facilities, vol. 18, no. 2, pp. 100-106, 2004.

[75] J. S. Davidson, J. W. Fisher, M. I. Mammons, J. R. Porter, and R. J. Dinan, "Failure mechanisms of polymer-reinforced concrete masonry walls subjected to blast," Journal of Structural Engineering, vol. 131, no. 8, pp. 1194-1205, 2005.

[76] M. Irshidat, A. Al-Ostaz, A. H.-D. Cheng, and C. Mullen, "Nanoparticle reinforced polymer for blast protection of unreinforced masonry wall: laboratory blast load simulation and design models," Journal of Structural Engineering, vol. 137, no. 10, pp. 1193-1204, 2011.

[77] S. Aghdamy, C. Wu, and M. Griffith, "Simulation of retrofitted unreinforced concrete masonry unit walls under blast loading," International Journal of Protective Structures, vol. 4, no. 1, pp. 21-44, 2013.

[78] Y. Su, C. Wu, and M. Griffith, "Mitigation of blast effects on aluminum foam protected masonry walls," Transactions of Tianjin University, vol. 14, no. 1, pp. 558-562, 2008.
[79] V. C. Li, "On engineered cementitious composites (ECC)," Journal of Advanced Concrete Technology, vol. 1, no. 3, pp. 215-230, 2003.

[80] M. Maalej, V. W. J. Lin, M. P. Nguyen, and S. T. Quek, "Engineered cementitious composites for effective strengthening of unreinforced masonry walls," Engineering Structures, vol. 32, no. 8, pp. 2432-2439, 2010. 


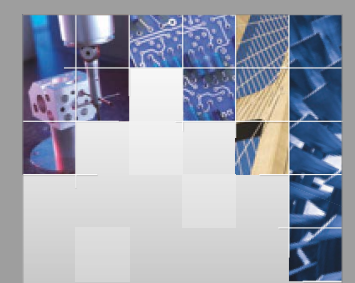

\section{Enfincering}
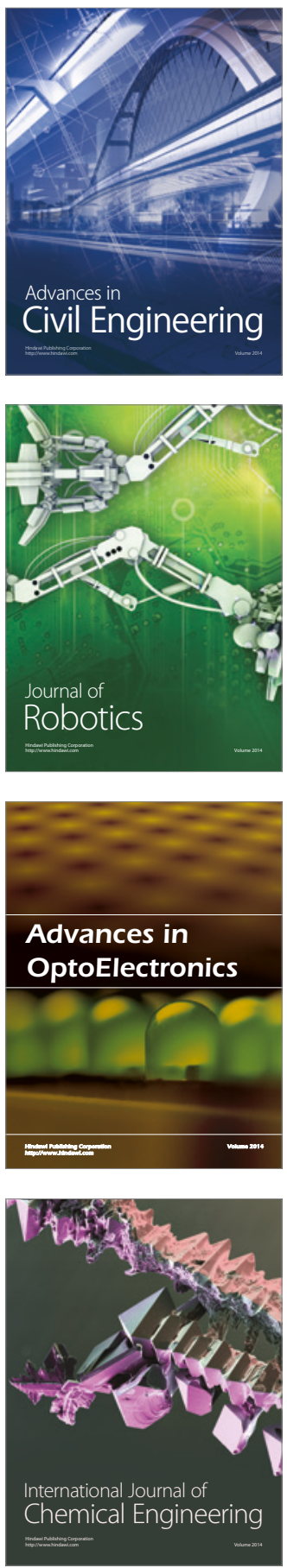

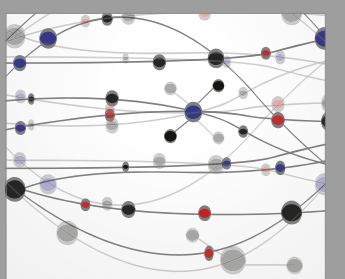

The Scientific World Journal

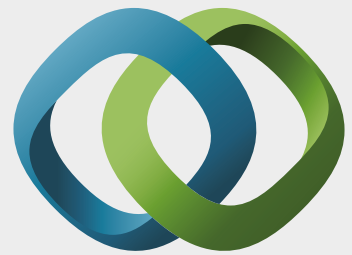

\section{Hindawi}

Submit your manuscripts at

https://www.hindawi.com
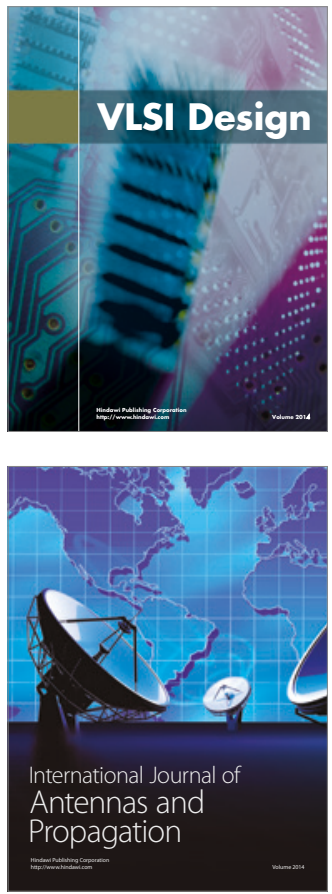

\section{Rotating}

Machinery
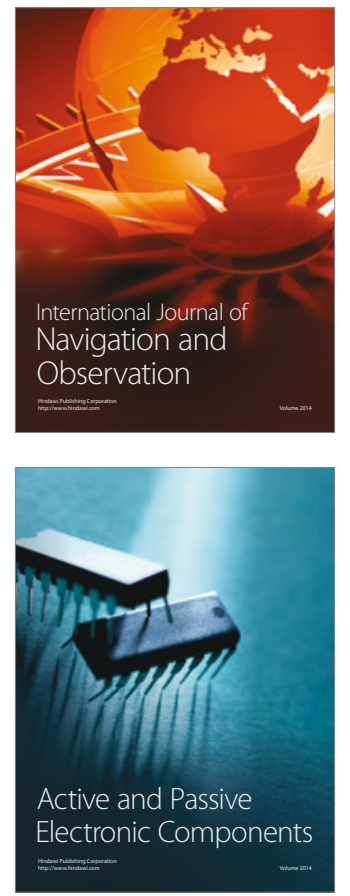
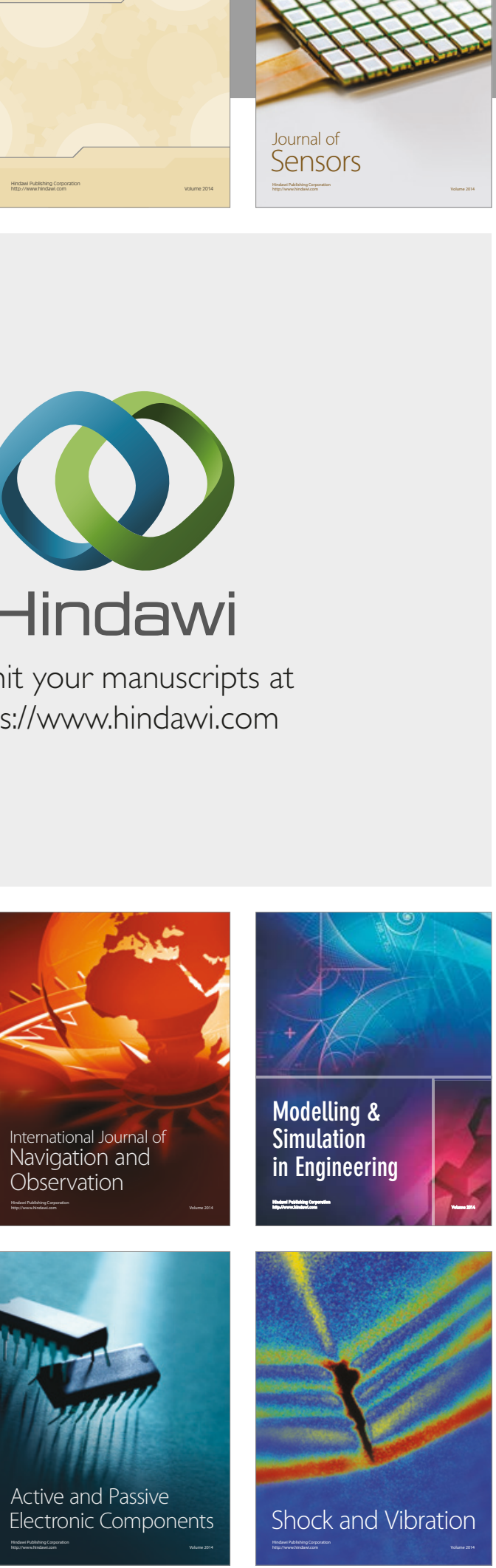
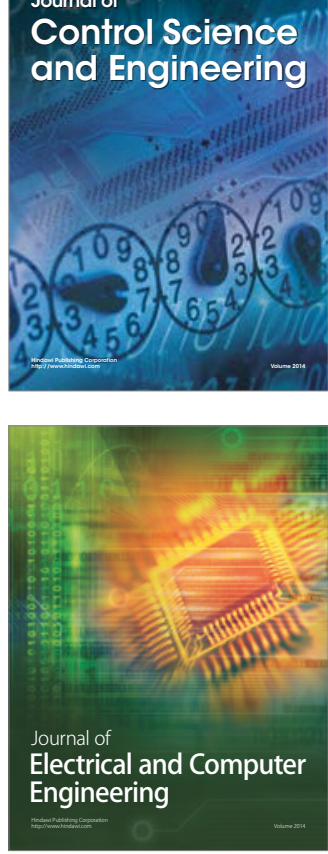

Distributed

Journal of

Control Science

and Engineering
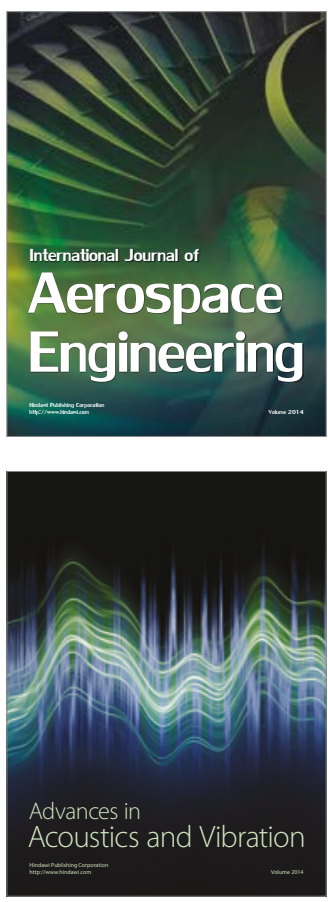

Sensor Networks 